\title{
Neighborhood-Level Predictors of Obesity Among African American Children in California
}

\author{
Uche Bibiana Onyeka \\ Walden University \\ Katie L. Callahan \\ Walden University and The University of Maine at Farmington \\ Manoj Sharma \\ Walden University, Jackson State University, and Health for All, Omaha, Nebraska
}

\begin{abstract}
The increased prevalence of childhood obesity is a major public health concern nationally and globally. Childhood obesity is primarily caused by the imbalance between caloric intake and caloric expenditure; however, its increase over the past decades may be due to environmental and behavioral factors. The purpose of the current study was to examine if any relationships existed between childhood obesity, level of physical activity, and neighborhood-level risk factors. This study used the California Health Interview Survey 2009-2014 data sets for African American children aged $5-11$ years $(n=1,049)$. The dependent variable was body mass index (BMI) while the predictors included physical activity, neighborhood, walkability, support, safety, and the presence of parks. Potential confounds were gender and parental education level. Chi-square tests were used to evaluate the associations between BMI and age, educational attainment, neighborhood walkability, physical activity, built environment, neighborhood support, and neighborhood safety. Multivariate logistic regression was used to assess the relationship between BMI and physical activity; parental educational level; presence of parks, playground, or open spaces; neighborhood walkability; neighborhood safety; neighborhood support; and gender while adjusting for other known risk factors. Low physical activity levels were a significant risk factor for increased obesity. No associations were discovered between childhood obesity and neighborhood safety; parental educational level; presence of parks, playgrounds, or open spaces; neighborhood walkability; neighborhood safety; neighborhood support; and gender. This study reinforces the relationship between environmental policy and physical activity.
\end{abstract}

Keywords: body mass index (BMI), child obesity, food insecurity, health behavior, healthy food environment, neighborhood safety, neighborhood support, neighborhood walkability, neighborhoodlevel factors, obesogenic factors, overweight, physical activity

This manuscript was completed in partial fulfillment of the doctoral requirements in Public Health at Walden University, under the direction of Katie L. Callahan and Manoj Sharma. 


\section{Introduction}

The rate of obesity among children and adolescents in the United States has tripled since the 1970s. According to the Centers for Disease Control and Prevention (CDC, 2018), 20\% of children aged 6 to 19 years in the United States are obese. Childhood obesity rates vary based on ethnicity, age, and gender, with girls experiencing more decreasing rates than boys (CDC, 2012). For instance, in 2017, approximately $14 \%$ of children ages $2-5$ years, over $18 \%$ of those aged $6-11$ years, and $21 \%$ of those aged 12-19 years are obese (CDC, 2018). The increasing prevalence of obesity has attracted much interest over the past few decades as a major public health problem. Cases of childhood obesity have increased progressively since the 1980s (Hruby \& Hu, 2015; Ogden, Carroll, Kit, \& Flegal, 2012). According to surveys from the CDC, the number of overweight children in the United States has increased over the past few years (Ogden et al., 2012). The reported obesity rates for non-Hispanic Asian, non-Hispanic White, non-Hispanic Black, and Hispanic girls are approximately 5.3\%, 15.1\%, $20.7 \%$, and $21.4 \%$, respectively (CDC, 2017).

In California, the estimated number of overweight children is $16 \%$, with approximately $17.2 \%$ being considered obese (CDC, 2014). The number of children in California who are affected by obesity and its related health conditions, as well as physical and economic costs, increased between 2009 and 2014 (California Department of Public Health [CDPH], 2016). Approximately 12.2\% of children between 6 and 11 years old were obese in 2009, with latest statistics indicating that this proportion slightly increased to $12.9 \%$ in 2016 (Let's Get Healthy California, 2016). In 2008, the estimated annual medical cost of obesity was approximately $\$ 86$ billion (Harvard School of Public Health, 2019). By 2014, the annual medical expenditure on obesity had risen to $\$ 149.4$ billion, which is mainly spent on weight management and addressing obesity-related comorbid conditions (Kim \& Basu, 2016). Currently, the impact of overweight and obesity on the United States has exceeded $\$ 1.7$ trillion, representing approximately $9.3 \%$ of the Gross Domestic Product (Waters \& Graf, 2018).

The California Health Interview Survey (CHIS) database is the largest survey and source of health data on the various ethnic and racial groups in California (Chi \& Handcock, 2014). The primary goal of CDPH is to improve access to enhance health outcomes, minimize the cost of care, and increase access to quality public health services by facilitating patient safety initiatives, screening, vaccinations, and other preventive programs (Chi \& Handcock, 2014). Similar studies using the CHIS dataset indicate that mental state of children and their consumption of fast foods influence their physical activity behaviors and risk of obesity (Banta, Khoie-Mayer, Somaiya, McKinney, \& Segovia-Siapco, 2013; Sturm \& Hattori, 2015). Healthy People 2020 aims to reduce the rate of obesity among children to $\leq 14.5 \%$ (Ogden et al., 2018). Though the obesity rates in California have met the national goal of the Healthy People 2020, more work is still needed to reduce the prevalence of obesity further. Research on this topic is important because disparities in obesity rates still exist; for instance, Californians with low household incomes, such as African Americans, have higher rates of obesity (Wolstein, Babey, \& Diamant, 2015).

CDPH (2016) reported obesity rates from data collected by the CHIS. Understanding the prevalence of obesity among children younger than 12 years in California has remained a challenge for health authorities. Similarly, data from the CHIS indicated that $15 \%$ of children in California ages $2-11$ were categorized as overweight or obese in 2014. The rate of overweight-for-age among California children declined to about $14.4 \%$ in 2011 and increased to $16.6 \%$ in 2014 (CDPH, 2016). The survey reported higher rates of $14.9 \%$ and $11.6 \%$ of overweight-for-age in boys than girls, respectively. African American and Latino children were $19.7 \%$ and $16.2 \%$ more likely to develop obesity rates, respectively, than non-Latino White children, who had a rate of $8.5 \%$.

The built environment in a specific neighborhood includes social and physical factors that shape the structure of community life in that location (Casey et al., 2014). Also, the built environment involves 
the manner in which a neighborhood is designed; the presence of schools, parks, and walking paths; and neighborhood safety (Sahoo et al., 2015). This suggests that children's physical activity levels could be influenced by population density, housing, and the presence of open or public spaces in the neighborhood. Roberts, Ray, Biles, Knight, and Saelens (2015) claimed that the changes in built environments have led to the rise in the number of restaurants and fast-food places and decreased space for sidewalks, parks, and recreational facilities in neighborhoods. These structures significantly influence children's physical activity behaviors, thus affecting their risk of obesity (Sallis, Floyd, Rodríguez, \& Saelens, 2012).

Sahoo et al. (2015) also discussed that the relationships children develop within a neighborhood influence their physical activity behaviors and weight status, which in turn determine their risk of developing obesity. According to Sahoo et al., children's environment plays a pivotal role in the increasing prevalence of childhood obesity. Because children spend prolonged time watching television and playing video games, when combined with environmental factors like unsafe neighborhoods, these contribute to increasingly sedentary lifestyles and reduction in physical activities. Borrell, Graham, and Joseph (2016) explained that neighborhood support was associated with neighborhood safety, thus could affect parents' willingness to allow their children to engage in physical activity out of doors. According to Borrell et al., perceived levels of social support in a neighborhood can significantly influence children's engagement in physical activity behaviors, hence affecting their risk of obesity. Borrell et al. concluded that children in unsupportive neighborhoods have a $20 \%$ higher risk of obesity compared to those living in supportive regions.

The immediate environment in which children grow can have a considerable effect on their nutrition and physical activity behaviors, thus influencing their risk of developing obesity. According to Tandon et al. (2012), secure neighborhoods have a lower prevalence of childhood obesity compared to locations with high rates of crime and violence. Yang, Jiang, Xu, Mzayek, and Levy (2018) concluded that neighborhood environment plays an important role in childhood overweight and obesity, whereas the effects vary by age, gender, and specific neighborhood characteristic. Neighborhood safety is one of the most important components of any community in the United States. Compared to children from secure neighborhoods, children living in unsafe communities seemed to engage in fewer physical activities such as cycling and walking (Borrell et al., 2016).

Duncan et al. (2014) found that neighborhood walkability among other neighborhood-level traits could significantly impact children's physical activity levels. Additionally, Kowaleski-Jones et al. (2017) mentioned that areas with high concentrations of traffic could inhibit physical activity behaviors; thus, increasing children's risk of becoming obese. Conversely, children who live in more walkable neighborhoods have lower risk of childhood obesity.

Mehtälä, Sääkslahti, Inkinen, and Poskiparta (2014) indicated that housing, population density, and the availability of public or open spaces in the neighborhood can also influence children's physical activity levels, thus affecting their body mass index (BMI). Similar results were found by Sandy, Tchernis, Wilson, Liu, and Zhou (2013), who concluded that land use and street connectivity can affect children's physical activity levels. Casey et al. (2014) found a strong relationship between the presence of food outlets, restaurants, and parks and high risk of childhood obesity. According to Carrol-Scott et al. (2015), children living in walkable neighborhoods with adequate spatial measurements have a lower risk of obesity because these environments promote physical activity behaviors.

Van Hulst et al. (2015) found that community disadvantage; neighborhood parks, sports, and recreational facilities; and convenience stores or fast food restaurants within children's living environment were neighborhood predictors of childhood obesity. However, the authors stated that it remains unclear how factors within these different levels (street connectivity and land use affect 
neighborhood walkability) influence children's physical activity levels and interact to determine obesity (Van Hulst et al., 2015). Other studies have also found a positive relationship between childhood obesity and the presence of parks, restaurants, and food outlets (Casey et al., 2014). Carroll-Scott et al. (2015) claimed that a significant relationship existed between the presence of schools and neighborhood environments and obesity among preadolescent children.

The literature review indicated that neighborhood-level factors including safety, support, walkability, and built environment may significantly influence children's physical activity behaviors and risk of obesity (Gunnarsdottir, Njardvik, Olafsdottir, Craighead, \& Bjarnason, 2011; Kimbro, Brooks-Gunn, \& McLanahan, 2011; Mehtälä et al., 2014; Williams, 2011). However, the extent to which these neighborhood-level factors influence childhood obesity has not been widely studied. Combined with the current rate of sedentary lifestyles, African American children have a higher risk of obesity compared to other races (Ogden et al., 2012). Thus, it was important to understand how neighborhood safety affected the BMI and risk of obesity among these high-risk children. Although research on the impact of neighborhood-level factors on childhood obesity is limited, a number of studies have indicated that neighborhood safety might be a serious risk factor for obesity among children (Casey et al., 2014; Roberts et al., 2015; Sahoo et al., 2015). The purpose of the present study was to evaluate the relationship between neighborhood-level factors and obesity among African American children aged 5-11 years living in California. The study assessed the BMI of African American children in relation to neighborhood predictors of childhood obesity such as physical safety, physical activity, parents' education level, neighborhood built environments, and neighborhood walkability.

\section{Method}

\section{Data Source}

Secondary data from UCLA-CHPR for the CHIS datasets from 2009 to 2013-2014 were used to study neighborhood predictors of childhood obesity on African American children aged 5-11years in California. The CHIS collects a wide range of data about individuals of all age groups regarding health status, health insurance coverage, health-related behaviors, demographic characteristics, and prevalence of chronic diseases. The CHIS employs telephone surveys that utilize random digit dialing (RDD) of the prospective samples' cellular telephone and landline numbers (CHIS, 2014). The CHIS is conducted by the University of California, Los Angeles (UCLA)-Center for Health Policy Research (CHPR), in collaboration with the CDPH, and the Department of Health Care Services (CHIS, 2014).

Data from the CHIS provided information on overweight-for-age because parental reports regarding children's heights may be inaccurate and unreliable. For this study, we calculated BMI based on selfreported weight and height and classified the participants as either obese or not obese based on the CDC's BMI for age percentile growth charts for children aged 2-20 years. Table 1 shows the CDC framework for classifying BMI for age and gender of children and adolescents ages 2-17 years. 
Table 1. Classification of Body Mass Index for Age and Gender of Children and Adolescents, Aged 2-17 Years

\begin{tabular}{lc}
\hline Classification & $\begin{array}{c}\text { Body Mass Index }\left(\mathbf{k g} / \mathbf{m}^{2}\right), \\
\text { Percentile Ranking }\end{array}$ \\
\hline Underweight & $\leq 4 \mathrm{th}$ \\
Normal or recommended weight & 5 th-84th \\
Overweight & 85th-94th \\
Obese & $\geq 95 \mathrm{th}$ \\
\hline
\end{tabular}

Note. Adapted from Centers for Disease Control and Prevention (2016).

The population of interest in this study was African American children in the state of California. The target sample included African American children aged 5-11 years in California. A power analysis using the $\mathrm{G}^{*}$ Power Version 3.1.9.2 tool was used to obtain the most appropriate sample size for the study. The minimum sample size for this particular statistical test with a power of 0.80 , a medium effect size of 0.30 , and an $\alpha$ of 0.05 was $n=557$ participants to detect a significant model (Creswell, 2014). The sample sizes for the respective CHIS surveys based on years were $2009(n=469), 2011$ ( $n$ $=153), 2012(n=209), 2013(n=128)$, and $2014(n=90)$. The response rates for each CHIS survey for years 2009, 2011-2012, and 2013-2014 were $72.9 \%, 73.2 \%$, and $68.9 \%$, respectively.

\section{Research Design and Statistical Analysis}

A quantitative correlational design was used to investigate the relationship between neighborhoodlevel factors and obesity among African American children in California. Four research questions guided this study:

Research Question 1: What is the association between neighborhood safety and BMI among African American children aged 5-11 years and living in California after adjusting for potential confounders?

Research Question 2: What is the association between neighborhood support and BMI among African American children aged 5-11 years living in California after adjusting for potential confounders?

Research Question 3: What is the association between neighborhood park/playground/open space safety and BMI among African American children aged 5-11 years living in California after adjusting for potential confounders?

Research Question 4: What is the association between physical activity and BMI among African American children aged 5-11 years in California after adjusting for other variables?

Multivariate logistic regression and chi-square tests were used to examine the relationship between neighborhood-level predictors and obesity using SPSS Version 22 software. Multivariate logistic regression was best suited for this quantitative project because it facilitated the evaluation of the association between neighborhood-level factors and obesity among African American children. The logistic regression model was used because the dependent variable was binary and the independent variables were categorical with mutually exclusive groups. This quantitative project was executed after considering three assumptions regarding logistic regression: dichotomous dependent variables, continuous or categorical independent variables, and mutually exclusive observations (Harrell, 2015). Children aged 5-11 years were interviewed by proxy, represented by an adult within the household with the most knowledge regarding their health. Unweighted data was used to facilitate more accurate findings (Meinck, 2015). 


\section{Results}

\section{Descriptives}

The total sample size of African American children aged 5-11 years living in California from 2009 to 2014 was $n=1,049$. Table 2 presents the total response rates of the CHIS surveys from 2009 to 2014 .

Table 2. Sample Distribution and Response Rates by California Health Interview Survey (CHIS) Year

\begin{tabular}{lcc}
\hline CHIS Year & $\begin{array}{c}\text { Total Sample } \\
\text { Size of CHIS }\end{array}$ & $\begin{array}{c}\text { African American } \\
\text { Children, } \boldsymbol{n} \text { (\%) }\end{array}$ \\
\hline 2009 & 8,945 & $469(5.2)$ \\
2011 & 3,488 & $153(4.4)$ \\
2012 & 3,846 & $209(5.4)$ \\
2013 & 2,920 & $128(4.3)$ \\
2014 & 2,592 & $90(3.5)$ \\
Total & 21,791 & $1,049(4.8)$ \\
\hline
\end{tabular}

The sample consisted of $52.2 \%$ boys and $47.8 \%$ girls. The largest proportion of the participants was aged 11 years (18.1\%), followed by those aged 10 years $(17.8 \%)$ and 9 years $(15.9 \%)$. The lowest proportion of the participants was 5 years old (11\%). Approximately one third of the participants (33.1\%) were obese. Close to half of the participants (44.8\%) felt safe in the neighborhood most of the time, $39.3 \%$ felt safe all of the time, and $13.6 \%$ felt safe only some of the time. Only $2.2 \%$ of the participants never felt safe in the neighborhood. Over half of the participants (57.1\%) lived in neighborhoods that could be trusted to look out for children; only $3.6 \%$ of the participants disagreed that adults in their neighborhoods could not be trusted to look out for children. Additionally, $89.3 \%$ of the children lived in neighborhoods with a park, playground, or open space within walking distance of their home. Over half of the participants (69.1\%) did not walk from school to home, and $34.1 \%$ engaged in at least $1 \mathrm{hr}$ of physical activity for 7 days in a week. About one fourth of the children's parents (24.1\%) had bachelor's degrees, $20 \%$ of the participants' parents had some college education, $18.6 \%$ had only high school diplomas, $12.9 \%$ had master's degrees, and $1.9 \%$ of the participants' parents had less than a Grade 8 education. Table 3 shows a detailed summary of the descriptive statistics of the study sample.

\section{Results of Chi-Square Tests}

Only age $(p=0.021)$ had a significant association with BMI. The findings indicated that the participants' age was positively correlated with their BMI. Thus, as the participants' age increases so also their BMI increases. The rest of the predictors showed no significant association with BMI: educational attainment $(p=0.908)$, neighborhood walkability $(p=0.116)$, physical activity $(p=$ $0.098)$, built environment ( $p=0.663)$, neighborhood support $(p=0.739)$, neighborhood safety $(p=$ $0.355)$, and age $(p=0.021)$. 
Table 3. Demographic Characteristics of the Study Sample $(\mathrm{N}=580)$

Demographic

Parents' highest education

Grade 1-8

n

Grade 9-11

Grade 12/diploma

Some college

Vocational school

Associate's degree

Bachelor's degree

Some graduate school

Master's degree

Doctorate degree

Days walked from school

0
1
2
3
4
5
7

Days of physical activity

0

1

2

3

4

5

6

7

Park/playground within walking distance

Yes

No

Adults in neighborhood look out for children

Strongly agree

Agree

Disagree

Strongly disagree

Not applicable

Feel safe in neighborhood

All of the time

Most of the time

Some of the time

None of the time

Age, years

5

6

7

8

9

10

11

Gender

Male

Female

Obesity

No

Yes $\%$

$n \quad \%$

$\begin{array}{rr}11 & 1.9 \\ 22 & 3.8 \\ 108 & 18.6 \\ 116 & 20.0 \\ 53 & 9.1 \\ 26 & 4.5 \\ 140 & 24.1 \\ 4 & 0.7 \\ 75 & 12.9 \\ 25 & 4.3\end{array}$

$401 \quad 69.1$

$22 \quad 3.8$

$\begin{array}{ll}4 & 0.7\end{array}$

$30 \quad 5.2$

$4 \quad 0.7$

$113-19.5$

$6 \quad 1.0$

$44 \quad 7.6$

$27 \quad 4.7$

$61 \quad 10.5$

$83 \quad 14.3$

$65 \quad 11.2$

$82 \quad 14.1$

$20 \quad 3.4$

$198 \quad 34.1$

$518 \quad 89.3$

$\begin{array}{ll}62 & 10.7\end{array}$

$132 \quad 22.8$

$331 \quad 57.1$

$90 \quad 15.5$

$21 \quad 3.6$

$6 \quad 1.0$

$228 \quad 39.3$

$260 \quad 44.8$

$79 \quad 13.6$

$13 \quad 2.2$

$64 \quad 11.0$

$72 \quad 12.4$

$67 \quad 11.6$

$77 \quad 13.3$

$92 \quad 15.9$

$103 \quad 17.8$

$105 \quad 18.1$

$303 \quad 52.2$

$277 \quad 47.8$

$388 \quad 66.9$

$192 \quad 33.1$ 


\section{Results of the Logistic Regression}

Only physical activity significantly predicted childhood obesity $(p=0.033)$. Parental educational level ( $p=0.842)$; presence of parks, playground, or open spaces $(p=0.595)$; neighborhood walkability $(p=0.374)$; neighborhood safety $(p=0.094)$; neighborhood support $(p=0.509)$; and gender $(p=0.617)$ did not significantly predict childhood obesity. Table 4 presents a summary of the first step of the logistic regression model.

Table 4. Multivariate Logistic Regression Results

\begin{tabular}{|c|c|c|c|c|c|c|c|c|}
\hline \multirow[b]{2}{*}{ Variables of Step 1a } & \multirow[b]{2}{*}{$\boldsymbol{B}$} & \multirow[b]{2}{*}{$S E$} & \multirow[b]{2}{*}{ Wald's $\chi^{2}$} & \multirow[b]{2}{*}{$d f$} & \multirow[b]{2}{*}{$p$} & \multirow[b]{2}{*}{$\operatorname{Exp}(B)$} & \multicolumn{2}{|c|}{ Odds Ratio (95\% CI } \\
\hline & & & & & & & $\begin{array}{l}\text { Lower } \\
\text { Limit }\end{array}$ & $\begin{array}{l}\text { Upper } \\
\text { Limit }\end{array}$ \\
\hline Physical activity & 0.086 & 0.040 & 4.528 & 1 & 0.033 & 1.090 & 1.007 & 1.180 \\
\hline Education level & & & 4.906 & 9 & 0.842 & & & \\
\hline Park & 0.162 & 0.305 & 0.283 & 1 & 0.595 & 1.176 & 0.647 & 2.140 \\
\hline Walkability & -0.041 & 0.046 & 0.791 & 1 & 0.374 & 0.960 & 0.878 & 1.050 \\
\hline Support & & & 3.302 & 4 & 0.509 & & & \\
\hline Safety & & & 6.404 & 3 & 0.094 & & & \\
\hline Gender & 0.092 & 0.184 & 0.251 & 1 & 0.617 & 1.090 & 1.007 & 1.180 \\
\hline Constant & -1.397 & 1.382 & 1.021 & 1 & 0.312 & 0.247 & & \\
\hline
\end{tabular}

Note. $\mathrm{CI}=$ confidence interval.

Table 5 shows the final regression model containing only physical activity, gender, and childhood obesity.

Table 5. Final Logistic Regression Model for Childhood Obesity, Physical Activity, and Gender

\begin{tabular}{|c|c|c|c|c|c|c|c|c|}
\hline \multirow[b]{2}{*}{$\begin{array}{l}\text { Variables of } \\
\text { Step } 1\end{array}$} & \multirow[b]{2}{*}{$B$} & \multirow[b]{2}{*}{$S E$} & \multirow[b]{2}{*}{ Wald's $\chi^{2}$} & \multirow[b]{2}{*}{$d f$} & \multirow[b]{2}{*}{$p$} & \multirow[b]{2}{*}{$\operatorname{Exp}(B)$} & \multicolumn{2}{|c|}{$95 \% \mathrm{CI}$ for $\operatorname{EXP}(B)$} \\
\hline & & & & & & & $\begin{array}{c}\text { Lower } \\
\text { Limit }\end{array}$ & $\begin{array}{l}\text { Upper } \\
\text { Limit }\end{array}$ \\
\hline Gender & 0.098 & 0.179 & 0.301 & 1 & 0.583 & 1.103 & 0.777 & 1.567 \\
\hline Physical activity & 0.085 & 0.039 & 4.636 & 1 & 0.031 & 1.088 & 1.008 & 1.567 \\
\hline Constant & -1.138 & 0.213 & 28.486 & 1 & 0.000 & 0.321 & & \\
\hline
\end{tabular}

Note. CI = confidence interval.

The final logistic regression model was as follows: obesity $=-1.138+0.085$ physical activity +0.098 gender. Only physical activity was significantly associated with childhood obesity $(p=0.031)$, odds ratio $=1.088$. The risk of obesity decreases with every additional increase in the number of days the children engaged in at least $1 \mathrm{hr}$ of physical activity in a week. The odds ratios indicated that boys were 1.103 times more likely to develop obesity compared to girls. Neighborhood safety was not significantly associated with obesity among African American children in California $(\mathrm{p}=0.314)$. After accounting for neighborhood walkability, built environments, parental education level, neighborhood safety, and age, no association was found between neighborhood support and childhood obesity $(p=0.515)$. There was no significant association between neighborhood built environment and childhood obesity after adjusting for age, neighborhood walkability, parental education level, built environments, and neighborhood safety $(p=0.764)$.

The researchers also evaluated whether the number of days children engaged in at least $1 \mathrm{hr}$ of physical activity affected their likelihood of obesity. In addition, there was no significant association between parental education level and childhood obesity $(p=0.842)$. No association was found between neighborhood walkability, and childhood obesity was not significant $(p=0.374)$. However, there was a significant relationship between obesity and the number of days in which the children 
participated in $1 \mathrm{hr}$ of physical activity ( $p=0.033$ ). The relationship between high risks for obesity was positive, implying that an increase in physical activity level leads to decreased obesity risk among the children.

\section{Discussion}

Neighborhood safety was not significantly associated with obesity among African American children in California. The findings of the present study are congruent with those of Datar, Nicosia, and Shier (2013), who suggested that parent perceptions of neighborhood safety is not a significant risk factor for childhood obesity. These authors reported that inconsistent and inadequate support for the association between neighborhood safety and leisure-time physical activity (Datar et al., 2013). However, the finding is inconsistent with previous studies indicating that safer neighborhoods increase children's daily physical activity compared to unsafe environments (Côté-Lussier, Mathieu, \& Barnett, 2015; Li, Barnett, Goodman, Wasserman, \& Kemper, 2013; Tandon et al., 2012). CôtéLussier et al. (2015) also found that neighborhood safety significantly influenced the amount of physical activity and exercise of children, adolescents, and adults. Li et al. (2013) found that lower levels of perceived neighborhood safety could reduce physical activity levels and increase the risk of obesity among children. Tandon et al. (2012) also found that neighborhood safety was a significant determinant of physical activity behaviors in children.

After accounting for neighborhood walkability, built environments, parental education level, neighborhood safety, and age, no association was found between neighborhood support and childhood obesity. The findings were inconsistent with Borrell et al. (2016), who found that parents who perceived that their children were safe and protected while outside their home were more willing to allow them to engage in leisure-time physical activity. The contrasting results in the present study may have resulted from the characteristics of the adult interviewees and possible confounds in the dataset. There was no significant association between neighborhood built environment and childhood obesity. The findings diverged from those of previous research on the subject of neighborhood built environments as a risk factor for childhood obesity. Various researchers have found that neighborhood built environments influence children's risk of developing obesity (Carroll-Scott et al., 2015; Casey et al., 2014; Mehtälä et al., 2014; Sandy et al., 2013). Mehtälä et al. (2014) stated that various environmental structures could influence children's physical activity levels, thus affecting their risk of obesity. Mehtälä et al. (2014) also found that neighborhood walkability, neighborhood safety, and the availability of recreational facilities significantly influenced physical activity levels among children.

In the present study, the researchers found a significant relationship between obesity and the number of days in which the children participated in $1 \mathrm{hr}$ of physical activity. Thus, while controlling for other neighborhood-level factors, children who engaged in physical activity more frequently were less likely to develop obesity. The findings suggested that the lack of physical activity was the primary risk factor for childhood obesity. The finding is consistent with Rech et al. (2012) who found that insufficient amount of physical activity could increase the likelihood of developing obesity among children. Rech et al. also found that physical activity among individuals was likely to result from their perceptions of neighborhood safety.

There was no significant association between parental education level and childhood obesity. This finding contrasted with Sarrafzadegan et al. (2013), who found that parental education played a significant role in children's participation in physical activity behaviors. Therefore, children whose parents have a high level of education are less likely to develop obesity, compared to those with parents who were illiterate or had low educational levels. The association between neighborhood walkability and childhood obesity was not significant. This finding was consistent with Hoyt et al. (2014), who found no association between neighborhood walkability and obesity risk. However, other 
studies indicate that neighborhood walkability influences children's physical activity behaviors, thus affecting their risk of obesity (Duncan et al., 2014; Kowaleski-Jones et al., 2017).

\section{Limitations of the Study}

The present study used secondary data from the CHIS, 2009-2014. However, secondary data can affect the reliability of a study due to various limitations (Creswell, 2014). For example, missing and unusual values in secondary data could negatively affect statistical power and influence the sample size, effect size, and confidence interval (Creswell, 2014). As a result, the confidence in which data are interpreted can be significantly affected. To minimize the impact of missing entries and unusual data in the current data set, we could have limited the analysis to a specific number of participants with complete entries. In this manner, a potential Type II error that occurs when one accepts a null hypothesis that is actually false could have been avoided.

One limitation of the current study was that the CHIS responses were based on parents' perceptions regarding their children's behaviors and characteristics including their weight, height, and race. Research has shown that parent-reported measurements are less accurate compared to those collected in clinical settings (Fisher, Mello, \& Dykens, 2014). However, because this study was conducted at a population level, self-reported measurements were often the only viable option and presented numerous benefits. In this quantitative study, the adults in each household were only interviewed regarding children aged 5-11 years. The use of self-reporting limited the present study in that the reliability and validity could not be investigated, thus increasing the possibility of bias in the findings (Fisher et al., 2014). As a result, the generalizability of the findings to the entire population of African American children in the United States is limited and should be used with caution. Additionally, self-reported data such as parents' educational attainments are personal factors; therefore, the participants may have been reluctant to share them candidly.

Another potential limitation of the current study was the unavailability of need-related risk factors of childhood obesity. For example, this study did not address the relationship between childhood obesity and food practices or physical education in the home and school environments or policyrelated risk factors. The present study also failed to examine other important predictors of the neighborhood environment including the availability of healthy foods, supermarkets, fast-food restaurants, traffic congestions, and neighborhood grocery stores. The inclusion of these risk factors would have provided a more comprehensive assessment of the impact of neighborhood-level predictors on childhood obesity among African Americans in California.

Another potential limitation of the present study was the failure to collect the parents' own weight statuses and physical activity levels or those of other children and adolescents in the household. As indicated in past research and focus groups, parents' prior experiences and physical activity behaviors can inform their decision to encourage children to engage in physical activity behaviors (Shen et al., 2016). Thus, comparing the parents' weight status to that of their children would have provided more information regarding the association between parental influence and childhood obesity. Some researchers have also demonstrated that self-reported weight and height of parents can be valid and reliable indicators of childhood obesity, especially when evaluating the relationship (Huybrechts et al., 2014). For example, a comparison of data from the National Health and Nutrition Examination Survey and the National Survey of Children's Health showed a close association between actual and parental reports of childhood obesity, BMI, and overweight estimates (Sugiyama et al., 2016).

A cross-sectional study by Sugiyama et al. (2016) involving 6,799 children ages 8-15 years evaluated data from the 2005-2014 data from the National Health and Nutrition Examination Survey. The children's BMI was calculated using measured heights and weights to classify children as either 
normal, underweight, overweight or obese based on reported weight status by the children or their parents. Parents' report of their children's weight status was based on healthcare professionals' description of their children's weight status. The study concluded with inaccuracy of children's or parents' perceptions of the children's weight status and recommends further study on the barriers of accurate perception of children's weight status, possible costs and benefits of promoting healthcare professionals' communication about the overweight or obesity status of children in clinical settings. Finally, the present study involved the use of a logistic regression model that calculated only the likelihood of a child's becoming obese, but not the causes of the condition. The use of quasiexperimental study design would have provided the opportunity to understand the causal relationships between childhood obesity and neighborhood-level predictors.

The use of unweighted data from the CHIS database in the present study is also a potential limitation. Unweighted can increase the likelihood of standard errors, thus, reducing the preciseness and accuracy of the findings (Iachan, Pierannunzi, Healey, Greenlund, \& Town, 2016). Unweighted data also introduces substantial design effect on findings (Iachan et al., 2016). However, unweighted data was used in this study to facilitate accurate findings of the relationship between neighborhoodlevel factors and BMI among children aged 5-11 years.

\section{Recommendations for Action}

This quantitative study has reiterated the existence of a gap in research relating to neighborhoodlevel predictors of childhood obesity. The findings help in addressing the gap by improving the understanding of the association between neighborhood-level factors and childhood obesity. Various recommendations for health practice can be drawn from the present study. For instance, schools should incorporate more educational programs and physical activity initiatives to reduce children's likelihood of developing obesity. In addition, parents should employ effective home-based interventions to ensure children engage in mandatory physical activity for at least $1 \mathrm{hr}$ daily to minimize the risk of obesity. The current study employed secondary data from the CHIS, 2009-2014. As a result, the investigator did not have control over the quality of data collected. Therefore, future research should be focused on the use of primary and researcher-collected data, as opposed to selfreported survey data to improve reliability. Because this study used unweighted data for data analysis, the authors of this research recommend future studies to use weighted CHIS data.

The present quantitative study offers numerous potential opportunities for future research. The findings of the present study provided additional evidence regarding the potential neighborhoodlevel factors for childhood obesity and highlighted important areas for future research with populations that have been largely overlooked such as African American and Latino communities. The findings of the present study may be useful in guiding future research regarding the problem of childhood obesity among African American children in California. For instance, the study can guide future research on parental influence on the risk of childhood obesity. The results can also be used in the development of home- and school-based interventions to improve physical activity levels and minimize the risk of obesity among low-income and minority populations in the United States.

The data used in this study were also collected using telephone interviews based on the CHIS questionnaire. However, using questionnaires to collect self-reported data can significantly improve the precision and accuracy of the responses, which could have limited the data analysis and interpretation. Assessment of the impact of neighborhood culture on childhood BMI and the risk of obesity could also be an interesting undertaking, especially among the minority groups in the United States. 


\section{Implications for Social Change}

Addressing the growing problem of childhood obesity in the United States is a challenging prospect. The ever-increasing complexity of the health care sector and difficulties in addressing chronic conditions such as childhood obesity reiterates the necessity of recruiting doctorate-prepared nurses to conduct research (Ogden, Carroll, Kit, \& Flegal, 2014). As there is a major gap in the research regarding the association between neighborhood-level predictors and obesity, several implications can be drawn from the results of the present study.

The findings of the present study contribute to the existing knowledge about childhood obesity and could be used to inform the development of policies to reduce and prevent the condition among minorities. In addition, this study can be utilized to initiate parental education on the benefits of regular physical activity among African American children in California. This improved knowledge and awareness may lead to a significant reduction in the rate of childhood obesity in California.

The findings of the present study can also guide the development of effective policies for enhancing physical activity and neighborhood environments. For instance, policymakers could use findings from this study to develop guidelines for physical activity behaviors among children. In addition, policymakers could use this study to guide policies involving the walkability of neighborhoods and the presence of parks and other recreational facilities.

\section{References}

Banta, J. E., Khoie-Mayer, R. N., Somaiya, C. K., McKinney, O., \& Segovia-Siapco, G. (2013). Mental health and food consumption among California children 5-11 years of age. Nutrition and Health, 22, 237-253. doi:10.1177/0260106015599511

Borrell, L. N., Graham, L., \& Joseph, S. P. (2016). Associations of neighborhood safety and neighborhood support with overweight and obesity in U.S. children and adolescents. Ethnicity \& Disease, 26, 469-476. doi:10.18865/ed.26.4.469

California Department of Public Health (CDPH). (2016). Obesity in California: The weight of the State, 2000-2014. Retrieved from https://www.cdph.ca.gov/Programs/CCDPHP/../RES_ObesityReport20002014.pd

California Health Interview Survey (CHIS). (2014). CHIS 2011-2012 methodology report series. Retrieved from http://healthpolicy.ucla.edu/chis/design/Documents/chis2011-2012-method2_2014-02-21.pdf

Carroll-Scott, A., Gilstad-Hayden, K., Rosenthal, L., Eldahan, A., McCaslin, C., Peters, S. M., \& Ickovics, J. R. (2015). Associations of neighborhood and school socioeconomic and social contexts with body mass index among urban preadolescent students. American Journal of Public Health, 105, 2496-2502. doi:10.2105/AJPH.2015.302882

Casey, R., Oppert, J. M., Weber, C., Charreire, H., Salze, P., Badariotti, D., \& Simon, C. (2014). Determinants of childhood obesity: What can we learn from built environment studies? Food Quality and Preference, 31, 164-172. doi:10.1016/j.foodqual.2011.06.003

Centers for Disease Control and Prevention (CDC). (2012). Prevalence of obesity in the United States, 2009-2010. Retrieved from http://www.cdc.gov/nchs/data/databriefs/db82.htm

Centers for Disease Control and Prevention (CDC). (2014). Data and statistics: Obesity and extreme obesity rates decline among low-income preschool children. Retrieved from http://www.cdc.gov/obesity/data/childhood.html 
Centers for Disease Control and Prevention (CDC). (2016). Body mass index (BMI). Retrieved from https://www.cdc.gov/healthyweight/assessing/bmi/

Centers for Disease Control and Prevention (CDC). (2017). Childhood obesity facts: Prevalence of childhood obesity in the United States, 2011-2014. Retrieved from https://www.cdc.gov/obesity/data/childhood.html

Centers for Disease Control and Prevention (CDC). (2018). Childhood obesity facts: Obesity facts. Retrieved from https://www.cdc.gov/healthyschools/obesity/facts.html

Chi, J. T., \& Handcock, M. S. (2014). Identifying sources of health care underutilization among California's immigrants. Journal of Racial and Ethnic Health Disparities, 1, 207-218. doi:10.1007/s40615-014-0028-0

Côté-Lussier, C., Mathieu, M. E., \& Barnett, T. A. (2015). Independent associations between child and parent perceived neighborhood safety, child screen time, physical activity and BMI: A structural equation modeling approach. International Journal of Obesity, 39, 1475-1481. doi:10.1038/ijo.2015.98

Creswell, J. W. (2014). Research design: Qualitative, quantitative, and mixed methods approaches (4th ed.). Thousand Oaks, CA: Sage.

Datar, A., Nicosia, N., \& Shier, V. (2013). Parent perceptions of neighborhood safety and children's physical activity, sedentary behavior, and obesity: Evidence from a national longitudinal study. American Journal of Epidemiology, 177, 1065-1073. doi:10.1093/aje/kws353

Duncan, D. T., Sharifi, M., Melly, S. J., Marshall, R., Sequist, T. D., Rifas-Shiman, S. L., \& Taveras, E. M. (2014). Characteristics of walkable, built environments and BMI z-scores in children: Evidence from a large electronic health record database. Environmental Health Perspectives, 122, 1359-1365. doi:10.1289/ehp.1307704

Fisher, M. H., Mello, M. P., \& Dykens, E. M. (2014). Who reports it best? A comparison between parent-report, self-report, and the real life social behaviors of adults with Williams Syndrome. Research in Developmental Disabilities, 35, 3276-3284. doi:10.1016/j.ridd.2014.08.011

Gunnarsdottir, T., Njardvik, U., Olafsdottir, A. S., Craighead, L. W., \& Bjarnason, R. (2011). The role of parental motivation in family-based treatment for childhood obesity. Obesity, 19, 16541662. doi:10.1038/oby.2011.59

Harrell, F. (2015). Regression modeling strategies with applications to linear models, logistic and ordinal regression, and survival analysis (2nd ed.). Nashville, TN: Springer.

Harvard School of Public Health. (2019). Economic costs: Paying the price for those extra pounds. Retrieved from https://www.hsph.harvard.edu/obesity-prevention-source/obesityconsequences/economic/

Hoyt, L. T., Kushi, L. H., Leung, C. W., Nickleach, D. C., Adler, N., Laraia, B. A., \&Yen, I. H. (2014). Neighborhood influences on girls' obesity risk across the transition to adolescence. American Academy of Pediatrics, 134, 942-949.

Hruby, A., \& Hu, F. B. (2015). The epidemiology of obesity: A big picture. PharmacoEconomics, 33, 673-689. doi:10.1007/s40273-014-0243-x

Huybrechts, I., Beirlaen, C., De Vriendt, T., Slimani, N., Pisa, P. T., Schouppe, E., . . Himes, J. H. (2014). Validity of instruction leaflets for parents to measure their child's weight and height at home: Results obtained from a randomised controlled trial. British Medical Journal Open, 4, e003768. doi:10.1136/bmjopen-2013-003768 
Iachan, R., Pierannunzi, C., Healey, K., Greenlund, K. J., \& Town, M. (2016). National weighting of data from the Behavioral Risk Factor Surveillance System (BRFSS). BioMed Central Medical Research Methodology, 16, 155. doi:10.1186/s12874-016-0255-7

Kim, D. D., \& Basu, A. (2016). Estimating the medical care costs of obesity in the United States: Systematic review, meta-analysis, and empirical analysis. Value in Health, 19, 602-613. doi:10.1016/j.jval.2016.02.008

Kimbro, R. T., Brooks-Gunn, J., \& McLanahan, S. (2011). Young children in urban areas: Links among neighborhood characteristics, weight status, outdoor play, and television watching. Social Science \& Medicine, 72, 668-676. doi:10.1016/j.socscimed.2010.12.015

Kowaleski-Jones, L., Zick, C., Smith, K. R., Brown, B., Hanson, H. \& Fan, J. (2017). Walkable neighborhoods and obesity: Evaluating effects with a propensity score approach. SSMPopulation Health, 3, 1-26. doi:10.1016/j.ssmph.2017.11.005

Let's Get Healthy California. (2016). Healthy beginnings/reducing childhood obesity: Obese youth are at greater risk for health problems, including Type 2 diabetes, high blood pressure, asthma, early maturation, and joint problems. Retrieved from https://letsgethealthy.ca.gov/goals/healthy-beginnings/reducing-childhood-obesity/\#

Li, J. S., Barnett, T. A., Goodman, E., Wasserman, R. C., \& Kemper, A. R. (2013). Approaches to the prevention and management of childhood obesity: The role of social networks and the use of social media and related electronic technologies-A scientific statement from the American Heart Association. Circulation, 127, 260-267. doi:10.1161/CIR.0b013e3182756d8e

Mehtälä, M. A. K., Sääkslahti, A. K., Inkinen, M. E., \& Poskiparta, M. E. H. (2014). A socioecological approach to physical activity interventions in childcare: A systematic review. International Journal of Behavioral Nutrition and Physical Activity, 11, 1. doi:10.1186/14795868-11-22

Meinck, S. (2015). Computing sampling weights in large-scale assessments in education. Survey Methods: Insights From the Field, 1-13. doi:10.13094/SMIF-2015-00004

Ogden, C. L., Carroll, M. D., Fakhouri, T. H., Hales, C. M., Fryar, C. D., Li, X., \& Freedman, D. S. (2018). Prevalence of obesity among youths by household income and education level of head of household-United States 2011-2014. Morbidity and Mortality Weekly Report, 67, 186-189. doi:10.15585/mmwr.mm6706a3

Ogden, C. L., Carroll, M. D., Kit, B. K., \& Flegal, K. M. (2012). Prevalence of obesity and trends in body mass index among U.S. children and adolescents, 1999-2010. Journal of the American Medical Association, 307, 483-490. doi:10.1001/jama.2012.40

Ogden, C. L., Carroll, M. D., Kit, B. K., \& Flegal, K. M. (2014). Prevalence of childhood and adult obesity in the United States, 2011-2012. Journal of American Medical Association, 311, 806814. doi:10.1001/jama.2014.732

Rech, C. R., Reis, R. S., Hino, A. A. F., Rodriguez-Añez, C. R., Fermino, R. C., Gonçalves, P. B., \& Hallal, P. C. (2012). Neighborhood safety and physical inactivity in adults from Curitiba, Brazil. International Journal of Behavioral Nutrition and Physical Activity, 9, 1. doi:10.1186/1479-5868-9-72.

Roberts, J. D., Ray, R., Biles, A. D., Knight, B., \& Saelens, B. E. (2015). Built environment and active play among Washington, DC, metropolitan children: A protocol for a cross-sectional study. Archives of Public Health, 73, 1-11. doi:10.1186/s13690-015-0070-3

Sahoo, K., Sahoo, B., Choudhury, A. K., Sofi, N. Y., Kumar, R., \& Bhadoria, A. S. (2015). Childhood obesity: Causes and consequences. Journal of Family Medicine and Primary Care, 4, 187192. doi:10.4103/2249-4863.154628 
Sallis, J. F., Floyd, M. F., Rodríguez, D. A., \& Saelens, B. E. (2012). Role of built environments in physical activity, obesity, and cardiovascular disease. Circulation, 125, 729-737. doi:10.1161/CIRCULATIONAHA.110.969022

Sandy, R., Tchernis, R., Wilson, J., Liu, G., \& Zhou, X. (2013). Effects of the built environment on childhood obesity: The case of urban recreational trails and crime. Economics \& Human Biology, 11, 18-29. doi:10.1016/j.ehb.2012.02.005

Sarrafzadegan, N., Rabeie, K., Nouri, F., Mohammadifard, N., Moatter, F., Roohafza, H., \& Pourmoghaddas, M. (2013). Parental perceptions of overweight and obesity of their children. Advanced Research Yields Across Atherosclerosis Journal, 9, 61-69.

Shen, B., Centeio, E., Garn, A., Martin, J., Kulik, N., Somers, C., \& McCaughtry, N. (2016). Parental social support, perceived competence and enjoyment in school physical activity. Journal of Sport and Health Science, 7, 1-7. doi:10.1016/j.jshs.2016.01.003

Sturm, R., \& Hattori, A. (2015). Diet and obesity in Los Angeles County 2007-2012: Is there a measurable effect of the 2008 "Fast-Food Ban"? Social Science \& Medicine, 133, 205-211. doi:10.1016/j.socscimed.2015.03.004

Sugiyama, T., Horino, M., Inoue, K., Kobayashi, Y., Shapiro, M. F., \& McCarthy, W. J. (2016). Trends of child's weight perception by children, parents, and healthcare professionals during the time of terminology change in childhood obesity in the United States, 2005-2014. Childhood Obesity, 12, 463-473. doi:10.1089/chi.2016.0128

Tandon, P. S., Zhou, C., Sallis, J. F., Cain, K. L., Frank, L. D., \& Saelens, B. E. (2012). Home environment relationships with children's physical activity, sedentary time, and screen time by socioeconomic status. International Journal of Behavioral Nutrition and Physical Activity, 9, 1-9. doi:10.1186/1479-5868-9-88

Van Hulst, A., Roy-Gagnon, M., Gauvin, L., Kestens, Y., Henderson, M. \& Barnett, T.A. (2015). Identifying risk profiles for childhood obesity using recursive partitioning based on individual, familial, and neighborhood environment factors. International Journal of Behavioral Nutrition and Physical Activity, 12, 1-9. doi:10.1186/s12966-015-0175-7

Waters, H., \& Graf, M. (2018). America's obesity crisis: The health and economic costs of excess weight. Retrieved from http://www.milkeninstitute.org/publications/view/944

Williams, J. E. (2011). Child obesity in context: Ecology of family and community. International Journal of Exercise Science, 4, 86-92.

Wolstein, J., Babey, S. H., \& Diamant, A. L. (2015). Obesity in California. Los Angeles, CA: UCLA Center for Health Policy Research. Retrieved from http://vid.chis.ucla.edu/publications/Documents/PDF/2015/obesityreport-jun2015.pdf

Yang, Y., Jiang, Y., Xu, Y., Mzayek, F., \& Levy, M. (2018). A cross-sectional study of the influence of neighborhood environment on childhood overweight and obesity: Variation by age, gender, and environment characteristics. Journal of Preventive Medicine, 108, 23-28. doi:10.1016/j.ypmed.2017.12.021 
The Journal of Social, Behavioral, and Health Sciences is an open-access, peer-reviewed, online interdisciplinary journal focusing on research findings that address contemporary national and international issues. Its objectives are to (a) encourage dialogue between scholars and practitioners in the social, behavioral, and health sciences that fosters the integration of research with practice; (b) promote innovative models of interdisciplinary collaboration among the social, behavioral, and health sciences that address complex social problems; and (c) inform the relationship between practice and research in the social, behavioral, and health sciences.

Walden University Publishing: http://www.publishing.waldenu.edu 